\title{
A Review on Acoustic and Skid Resistance Solutions for Road Pavements
}

\author{
Sergio Copetti Callai *(D) and Cesare Sangiorgi (D) \\ Department of Civil, Chemical, Environmental and Materials Engineering, University of Bologna, \\ 40136 Bologna, Italy; cesare.sangiorgi4@unibo.it \\ * Correspondence: sergio.copetticalla2@unibo.it
}

Citation: Copetti Callai, S.; Sangiorgi, C. A Review on Acoustic and Skid Resistance Solutions for Road Pavements. Infrastructures 2021, 6, 41. https://doi.org/10.3390/

infrastructures6030041

Academic Editor: Fabrizio D'Amico

Received: 4 February 2021

Accepted: 8 March 2021

Published: 11 March 2021

Publisher's Note: MDPI stays neutral with regard to jurisdictional claims in published maps and institutional affiliations.

Copyright: (C) 2021 by the authors. Licensee MDPI, Basel, Switzerland. This article is an open access article distributed under the terms and conditions of the Creative Commons Attribution (CC BY) license (https:/ / creativecommons.org/licenses/by/ $4.0 /)$.

\begin{abstract}
As cities grow in size, traffic also increases, thus making the population more exposed to road noise and traffic accidents. It is therefore important to study and understand which properties of the pavement influence its acoustic impact and skid resistance performance. The pavement texture plays a major role in generating noise and friction, and it can be engineered in order to control both of them at the same time. The phenomena regulating skid resistance are well understood today. The same applies for noise generation and propagation; the literature contains methods of designing the pavement surface layer to achieve consistent results. Several types of solutions can be found for asphalt mixtures, most of them derived from decades of studies and research. They use different approaches to be effective for noise and friction, but all have in common the control of the surface's macro and microtexture. Finally, some considerations are made regarding novel paving solutions with artificial aggregates instead of natural ones to address noise and skid resistance.
\end{abstract}

Keywords: road noise; skid resistance; quiet pavements; polished stone value; microsurfacing

\section{Introduction}

The main function of highway pavement is to withstand traffic and allow mobility in a safe, comfortable, and economical way by distributing the surface loads to the existing natural subgrade [1]. As pavement is the main structural element of the road infrastructure, it must provide a durable, solid structure capable of withstanding the traffic loads carried during its service life without suffering damages that can eventually reduce its safety. Along with the structure, the pavement's surface functional performance is a key factor, due to its direct relation to safety, riding quality, noise, and appropriate visibility at night and in adverse weather conditions [2].

Among the mentioned aspects of road pavement's structure and surface, traffic noise has become one of the major environmental concerns of densely populated areas worldwide. In fact, road vehicles are, by virtue of their numbers, their traveling speeds, and their strong output, a powerful sound source [3]. Indeed, population growth in urban areas has increased traffic, thus increasing noise sources and receivers and hence affecting the quality of life and, eventually, the health of people [4,5].

With a focus on the asphalt concrete surface of roads, the pavement's texture appears to be a crucial aspect that can be controlled by the type and sizes of aggregates, type of asphalt binder, and through the laying processes. Control of these variables can increase friction, reduce water spray and splash, and abate noise. Following the surface texture description, pavement roughness can be divided into four texture wavelengths: unevenness, megatexture, macrotexture, and microtexture [6]. Each range interacts with the vehicle and its tires in a different manner. However, macro and microtextures are the most relevant ones, since they have the strongest influence on noise and friction. A higher macrotexture with similar microtextures has a greater influence on the friction than surfaces with similar microtextures and lower macrotextures [7]. Pavement surfaces with the same macrotexture and microtexture can also differ due to the spatial distribution of the particles in reference 
to a baseline. The literature shows that pavements with a positive texture (more peaks) usually have higher noise levels than those with a similar macrotexture but arranged in a negative manner (more valleys) $[8,9]$.

The term skid resistance is generally used to describe the pavement's contribution to the development of friction. It denotes a measurement of friction obtained under standardized conditions, in which the various parameters are controlled so that the effects of the road surface characteristics can be isolated $[10,11]$. Other studies show that skid resistance and friction can be controlled by the pavement texture. A higher macrotexture and a higher microtexture often results in higher friction, thus reducing accident risks [12]. Adequate texture on the pavement surface is required to provide skid resistance at the tire-road interface for vehicle safety in wet conditions [13,14].

This paper aims to offer a review of the depicted topic by discussing pavement texture properties and their relation to skid resistance and noise. Besides that, a pioneering asphalt pavement solution is presented, which combines the noise abatement and skid resistance properties due to the adoption of innovative engineered artificial aggregates.

\section{Road Pavement Surface Properties}

\subsection{Texture}

The pavement texture is defined as the deviation of a pavement surface from a true planar surface, caused by the random arrangement of the surface elements and their superficial roughness [15]. The texture of the pavement and its interaction with the tire can have desirable and undesirable outcomes, ranging from a high skid resistance (desirable) to discomfort and wear in the vehicle (undesirable). These effects mainly depend on the wavelength range of the texture, as shown in Figure 1. The International Standards Organization (ISO) [15] identified the different orders of the texture of a road pavement:

- The microtexture covers wavelengths that are of the same order as the texture of the aggregates with wavelengths below $0.5 \mathrm{~mm}$;

- The macrotexture covers wavelengths of the same order of size as the tire tread elements (i.e., from $0.5 \mathrm{~mm}$ to $50 \mathrm{~mm}$ );

- Wavelengths over $50 \mathrm{~mm}$ correspond to the megatexture and unevenness.

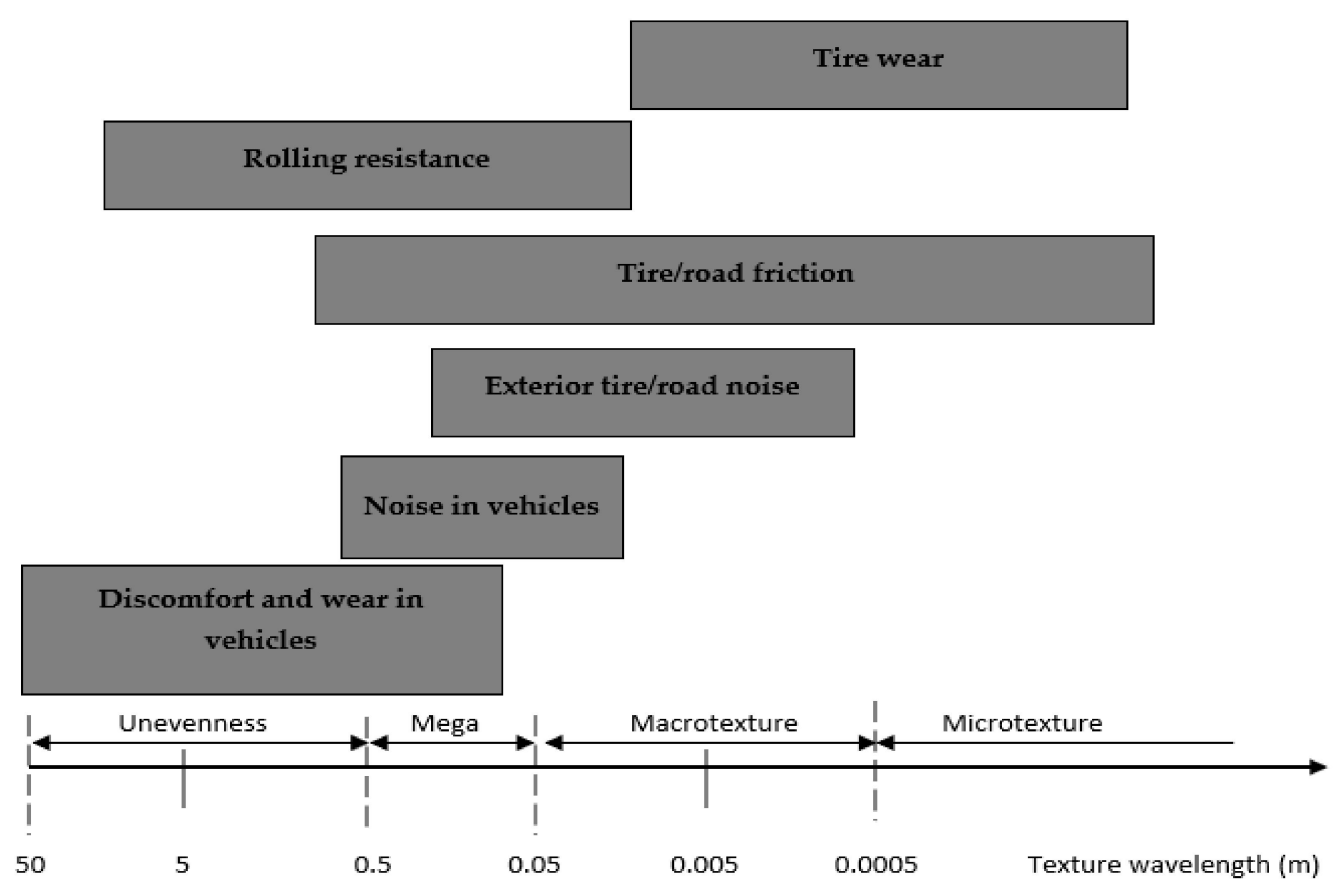

Figure 1. Tire-pavement interactions and ranges of the texture wavelength and spatial frequency (adapted from [16]). 
Unevenness and megatexture are usually undesirable for textures, while road friction and tire-road noise can be regulated by controlling the macrotexture and microtexture. The macrotexture is primarily influenced by the size, shape, and gradation of the coarse aggregates. It is mainly the nominal maximum aggregate size [17] that governs the surface 3D geometry and the other parameters affecting the volumetrics of the asphalt surface. As for microtexture, it is primarily influenced by the aggregate particle mineralogy that affects the initial texture of the aggregate and its capability to preserve the texture due to the polishing action of traffic and environmental actions [17].

It has been proven that the texture of the pavement can have a given wavelength. However, it may have a different outcome when interacting with the tire due to how this wavelength is distributed on the pavement. It is considered positive when its particles are protruding above the plane of the surface. The texture can also be negative, which is when it is comprised of voids between the particles and usually has a flat rolling surface. Both situations are represented in Figure 2.

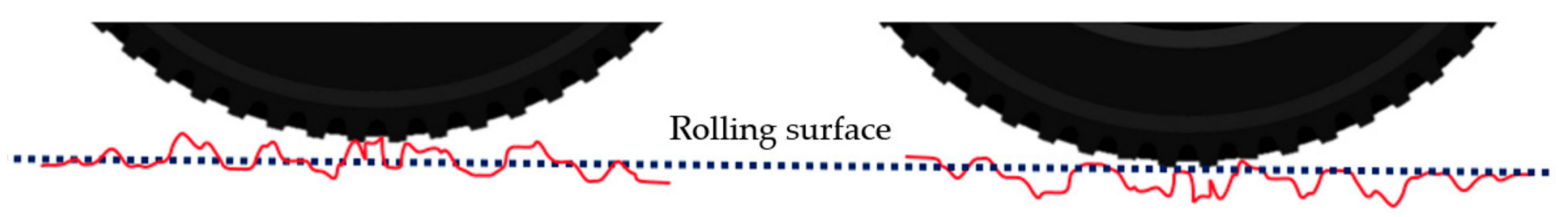

(a)

(b)

Figure 2. Schematic representation of a positive texture (a) and negative texture (b).

According to researchers, depending on the size of the particles, positive texturing leads to higher indentation levels in the rolling tire, thus having good results for the skid resistance. In comparison, negative textures contribute to lower noise levels due to the valleys' predominance [18-20]. The surface arrangement of the texture, positive or negative, is of the highest importance. It has been reported that a negative texture results in a decrease of rolling noise, while the positive texture is more detrimental from an acoustical point of view [21]. Research has been conducted on how to achieve better skid resistance and lower noise, as is described in the following sections.

\subsection{Skid Resistance}

Concerning the Sustainable Development Goals devoted to the health and well-being of the population (SDG $n^{\circ} 3$ ) and the sustainability of cities and communities (SGD $n^{\circ} 11$ ), different research shows that when the pavement texture design has improved, the risk of accidents is significantly reduced [22-24]. According to the World Health Organization (WHO) report on traffic, road traffic injuries are among the top leading causes of death for people of all ages [25]. The death toll was rising, and it reached 1.35 million in 2016. Hence, road traffic crashes constitute an important public issue with significant health and socioeconomic costs, which should be tackled by road agencies and research $[25,26]$.

The interaction between the tire and pavement, which governs vehicle driving actions, depends upon the pavement's surface characteristics (including its contamination) and the tire's mechanical and physical properties. Skid resistance is the force developed when a tire that is prevented from rolling starts to slide on the pavement [27]. This interaction is usually identified with the skid resistance, which is defined as a measure of the friction phenomena that have a direct and important effect on perceived and quantified road safety [8].

For instance, the existing data plotted in Figure 3 show that as the coefficient of friction (given as a parameter of the skid resistance) increases, the crash rate is reduced. The crash rate (every $10^{8}$ vehicles-km) is plotted here against Sideway-force Coefficient Routine Investigation Machine (Scrim) data from the Scrim. 


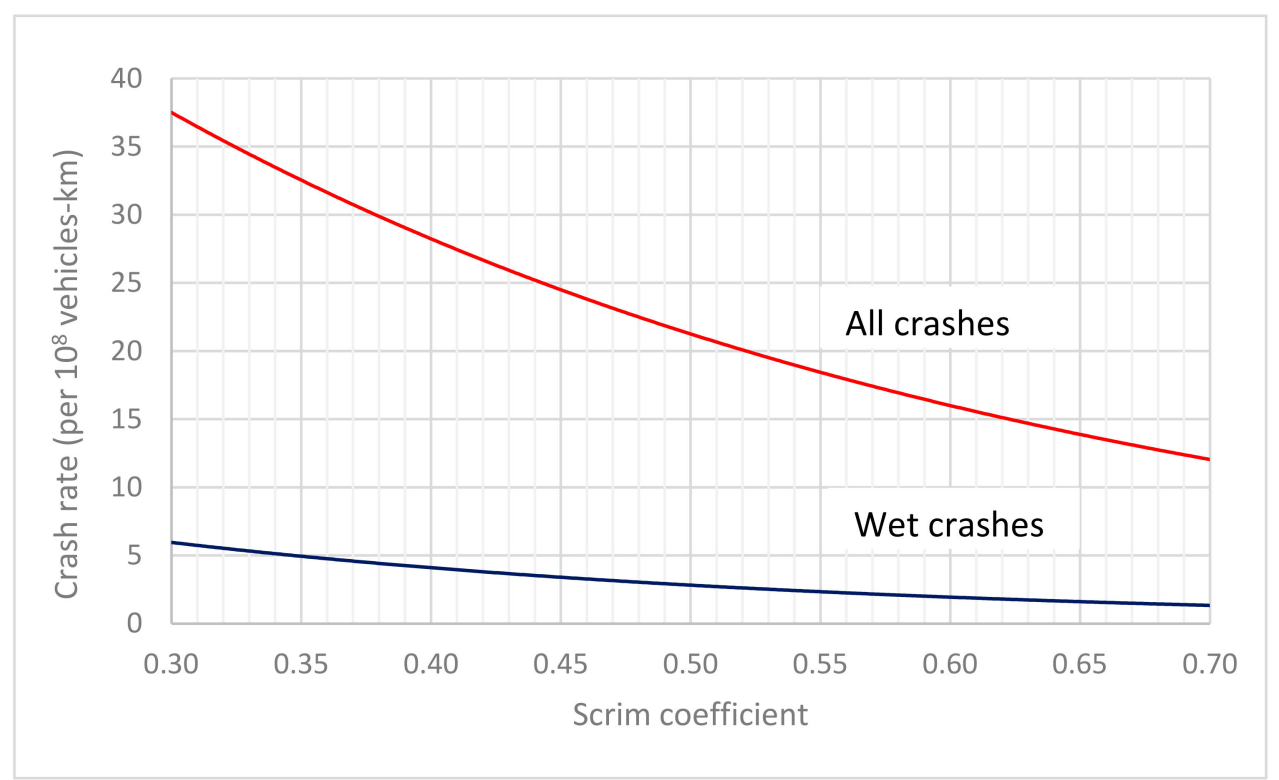

Figure 3. Sideway-force Coefficient Routine Investigation Machine (Scrim) coefficient vs. crash rate (adapted from [22]).

The skid resistance of pavement, especially in wet conditions, is of the utmost importance. In fact, a set of studies showed that approximately $20 \%$ of all road accidents occur when the surface is wet $[26,28]$.

In theory, the available skid resistance is given by the frictional forces developed at the tire-road interface, which are partially governed by the surface properties of the pavement (e.g., the texture and its level of contamination) [29]. Moreover, the geometrical dimensions and the aggregates' source are relevant properties, as far as skid resistance development is concerned. This is because the aggregates' mineralogy can affect the resistance to polishing (hence the aggregate's microtexture). It should be recalled that the microtexture of the surface aggregates and the overall macrotexture is directly related to the two main components of the friction, which are hysteresis and adhesion, as represented in Figure 4 [30,31].

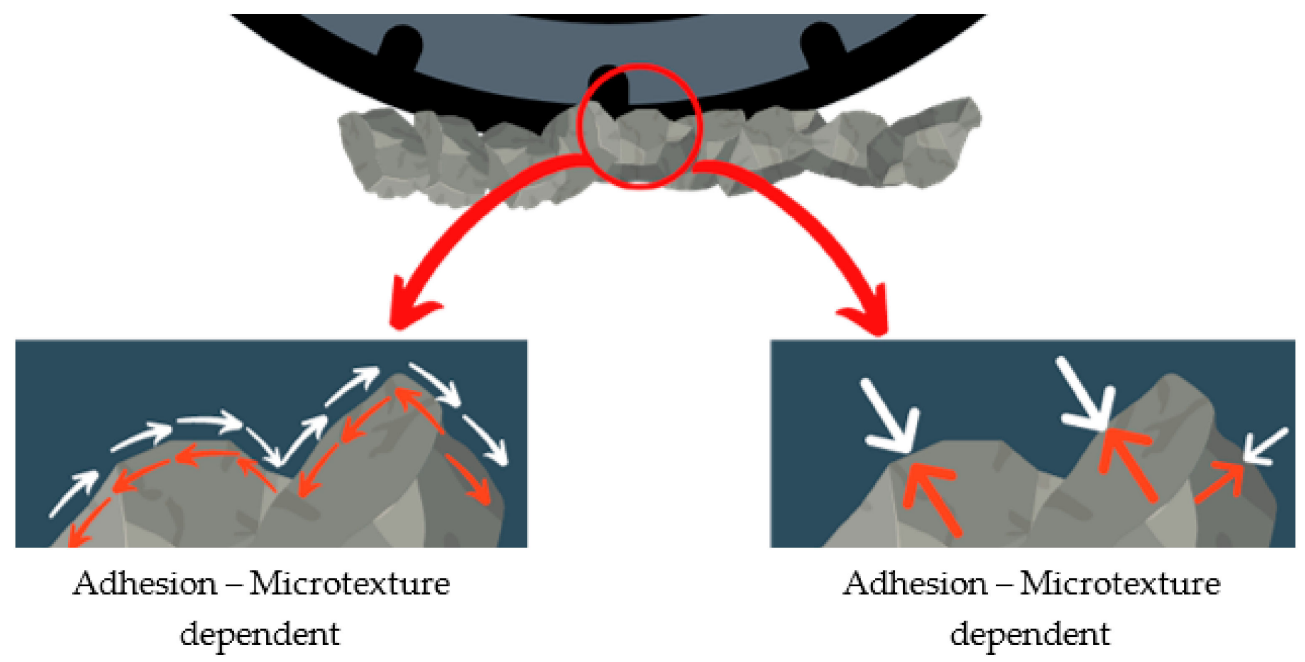

Figure 4. Key parameters of pavement-tire interaction (adapted from [30]).

Both phenomena concur to regulate friction. The adhesion is the friction that results from the small-scale bonding of the tire's rubber and the pavement surface, while the hysteresis results from the energy loss due to the bulk deformation of the tire rubber when it deforms against the pavement surface. The stress causes the deformation energy to be 
stored within the rubber [30]. The adhesion is often neglected because when the texture is positive, the hysteretic part is more relevant to increasing the skid resistance. However, this behavior changes once the texture becomes smoother [32], with fewer peaks and valleys. The presence of contaminants or water can influence both adhesion and hysteresis, which will decrease the number of contact points needed for friction to occur.

\subsection{Noise}

Noise pollution from roads has major effects on people's health [33]. Studies indicate that it is directly related to several common diseases, such as cardiovascular ones, myocardial infarction, deafness, and depression. Noise also has an influence on the birth rate, work-related stresses, and productivity, as well as the impairment of learning of children in schools [34-37].

According to the Imagine-Project [38], tire-pavement noise is the most relevant component of overall traffic noise at speeds over $40 \mathrm{~km} / \mathrm{h}$, as represented in Figure 5 . The overall noise is mainly given by propulsion and tire-pavement noises, which are both speed-dependent, but tire-pavement prevails at speeds over $30 \mathrm{~km} / \mathrm{h}$ for car traffic and for trucks when their speed is above $75 \mathrm{~km} / \mathrm{h}$ [38].

\section{Passenger vehicle}

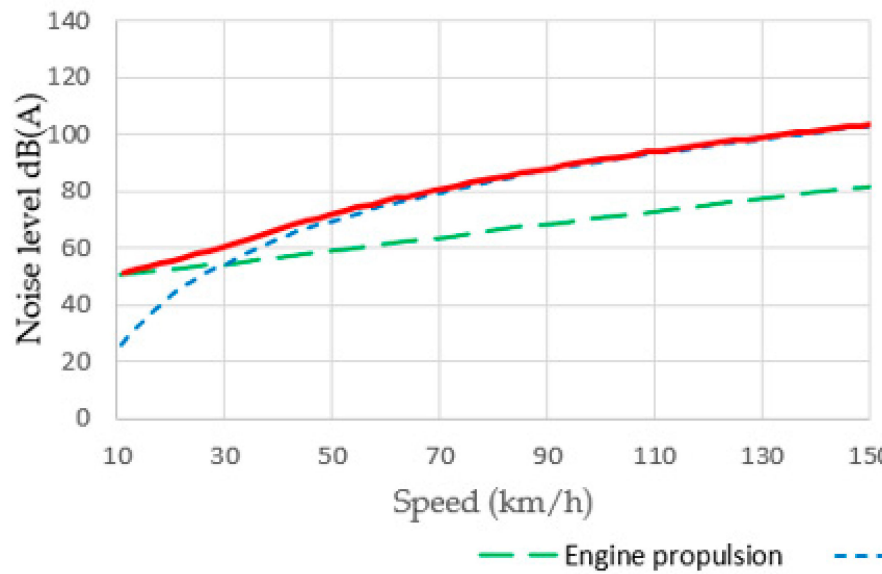

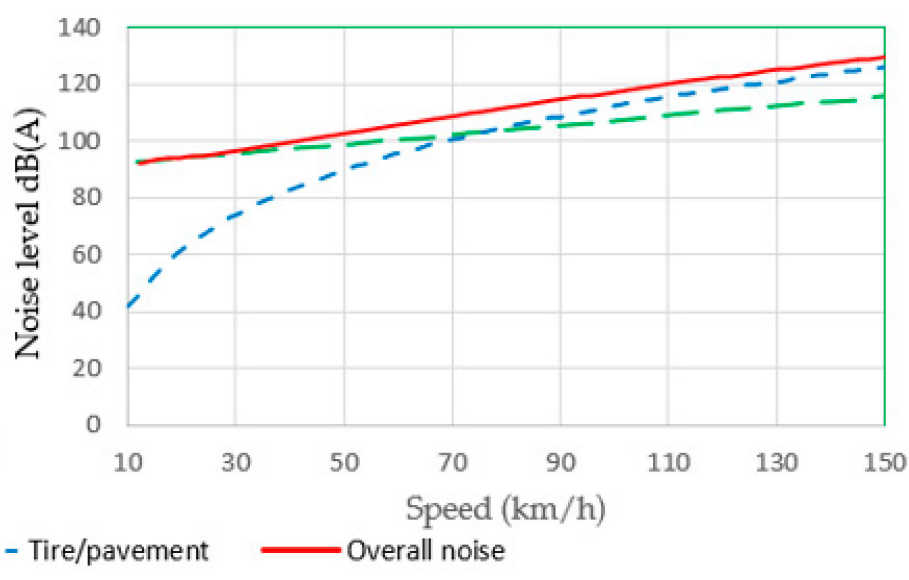

Overall noise

\section{Commercial vehicle}

Figure 5. An estimate of passenger and commercial vehicle noise and its main sources (adapted from [38]).

It is important to notice that even at higher speeds, if the tire-pavement noise is reduced, it is possible to mitigate the overall noise; the noise levels are on a logarithmic scale.

The most important noise generation mechanisms and propagation have been identified $[3,30]$, as represented in Figure 6. Road engineers can design road surfaces by focusing on these mechanisms, aiming for the most appropriate material selection to achieve specific layer characteristics.

The tire-pavement interaction related to noise consists of three main generation and amplification or reduction phenomena. Vibrational mechanisms are deformations related to impact and tire rolling, mainly on the hysteretic component, and adhesion mechanisms are mainly related to the adhesion component of the interaction. They are highly dependent on the tire characteristics, as well as the pavement material and texture. The aeroacoustics depend mainly on the geometry of the tire-pavement contact and the number of air voids. The amplification or reduction also depends on the geometry and the mechanical and acoustic absorption properties of the pavement. For instance, to reduce the tire tread impact noise generation, a lower layer stiffness can be achieved by means of asphalt rubber or rubberized asphalt. Similarly, aggregate selection can be targeted to improve the microtexture, thus addressing the noise generation mechanisms related to surface adhesion (e.g., the stick and slip and the stick and snap). 
Noise generation and propagation can also be attenuated or mitigated by reducing the pavement surface layer's stiffness by increasing its porosity while reducing the size of the aggregates and making its texture negative [39] or adding rubber to the asphalt mixture $[40,41]$. There are studies which aimed to model the texture and predict the noise [42-44].

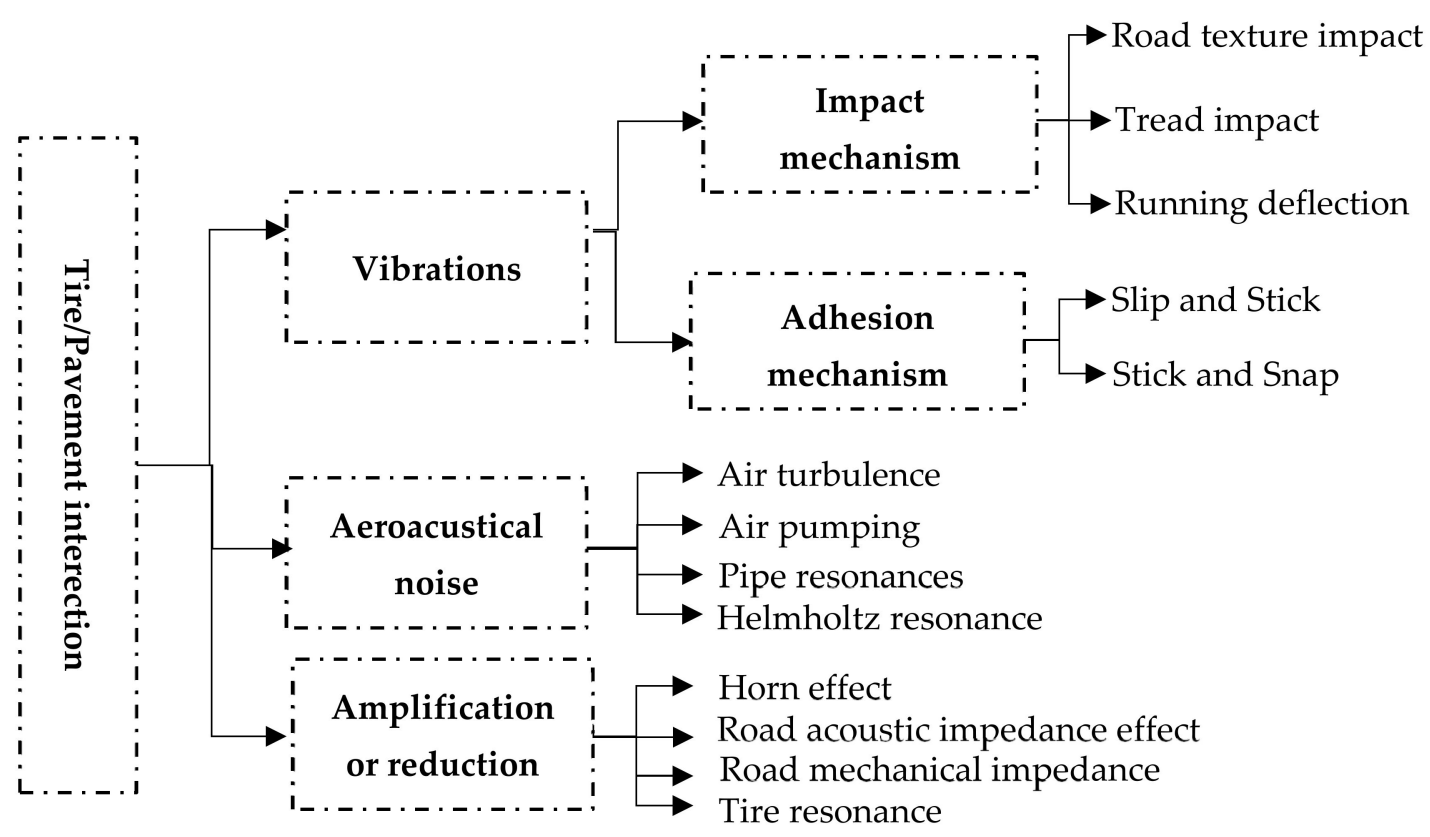

Figure 6. Road noise mechanisms due to tire-pavement interaction (adapted from [14]).

In Figure 7, it is shown that the skid resistance increases as the noise increases. This can be due to many factors, but because the most important ones are the texture depth and whether the surface is positive or negative, it should be considered that it is quite difficult to achieve a low noise surface while recording very high skid resistance. It is usually a tradeoff that should also consider other pavement characteristics, above all the durability.

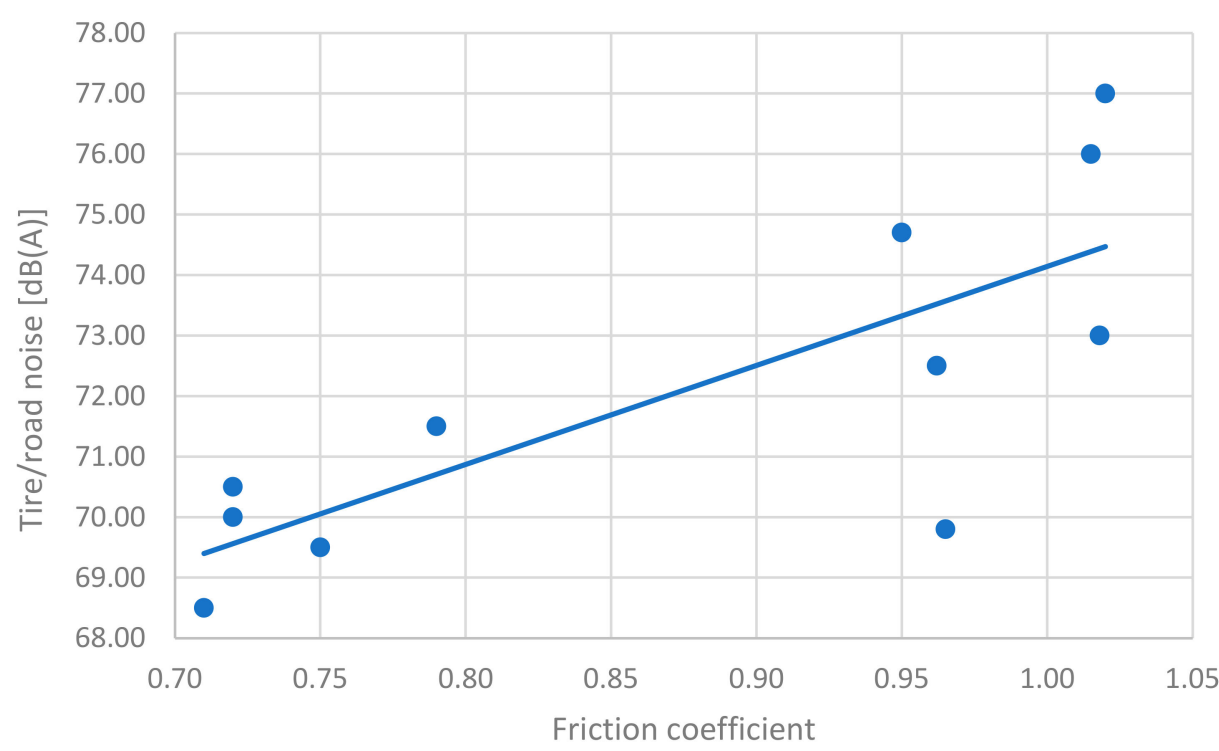

Figure 7. Noise level versus friction coefficient on a dry pavement (adapted from [45]).

\section{Existing Pavement Solutions to Address Noise Pollution and Skid Resistance}

Several different asphalt layer alternatives vary in terms of the sieve size distribution (open-graded, dense, or gap-graded), type of binder, production and laying processes, 
pavement stratigraphy, and other connected variables. These alternative pavements might be suitable to perform as acoustic surfaces, improve the wearing course skid resistance, or in some cases, to target a compromise between both aspects. In the following sections, each type of pavement will be briefly described, and comments on their main characteristics will be given in terms of their acoustic or skid resistance performance.

\subsection{Dense-Graded Hot Mix Asphalt}

Dense-graded asphalt concrete is the base benchmark for all comparisons, because it is the most common asphalt pavement and is the commonly used pavement for comparing standardized noise measurements [46]. It has a dense aggregate gradation curve with a low amount of air voids in the compacted mixture. Since it is not produced as acoustic pavement, it has, in principle, no noise reduction capabilities, but proper selection of the particle size distribution can lead to reduced noise impacts. The sound pressure levels are usually as high as $84 \mathrm{~dB}(\mathrm{~A})[47,48]$, while the initial friction values are approximately 60-65 BPN [48]. Variations in data are obviously expected according to the gradation size, aggregate type, and mixture proportions.

\subsection{Open-Graded Friction Courses}

According to Alvarez et al. [49], open-graded friction courses are special gap-graded asphalt mixtures that are known for having a large proportion of interconnected air voids. This volumetric property results in large permeability values and noise reduction capabilities, with the air void contents ranging between $15 \%$ and $35 \%$. Due to its porosity and aggregate gradation, this asphalt concrete has a negative texture, and it can mitigate noise with sound pressure level differentials of approximately $3.5 \mathrm{~dB}(\mathrm{~A})$ at standard speeds. The usual levels can range from 74 to $76 \mathrm{~dB}(\mathrm{~A})$ [50]. As for friction, the initially measured values can range from 50 to $70 \mathrm{BPN}$ [51]. Moreover, it has positive performance in wet conditions because its permeability reduces the water spray and splash phenomena.

\subsection{Stone Mastic Asphalt (SMA)}

Stone mastic asphalt (SMA) was developed in Germany in the 1960s as a solution for paving heavily trafficked roads. The asphalt layer has a high content of coarse aggregates, which forms a gap-graded, skeleton-like stone structure [52], as shown in Figure 8. SMA has a low air void content. However, it can mitigate the noise pressure levels up to $2-3 \mathrm{~dB}(\mathrm{~A})[53,54]$, with typical values ranging from 76 to $80 \mathrm{~dB}(\mathrm{~A})$ [55]. The selection of an appropriate aggregate size is crucial to achieving consistent noise mitigation. SMA has good behavior regarding friction, with values ranging from 50 up to 65 BPN [56].

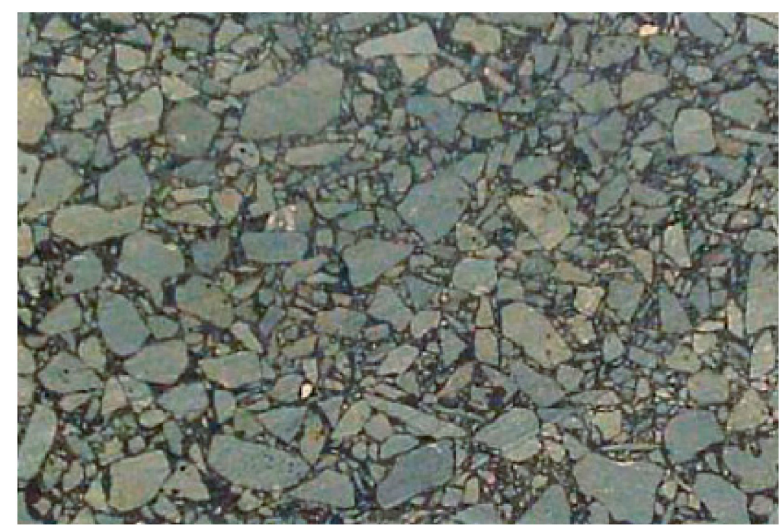

Figure 8. The inner section of a typical stone mastic asphalt (SMA) compacted layer [54].

\subsection{Porous Elastic Road Surface (PERS)}

Porous elastic road surface (PERS), Figure 9, is made with rubber, usually from scrap tires, and it has a $20-40 \%$ air void content. The rubber content comprises about 
$20 \%$ of the volume of the total mix. This pavement type is still experimental, and more research is required to confirm its performance in terms of durability and safety $[3,53,54]$. However, as it has a low stiffness modulus and is highly porous, it can effectively mitigate noise, achieving results that can potentially reach differentials up to $10 \mathrm{~dB}(\mathrm{~A})[57,58]$. Studies conducted by Goubert [54] and Ejsmont et al. [57] stated that the noise reduction could be as high as $12 \mathrm{~dB}(\mathrm{~A})$, and the skid resistance was around $60 \mathrm{BPN}$, which was acceptable. However, more studies should be conducted to assess the skid resistance values' consistency [59].
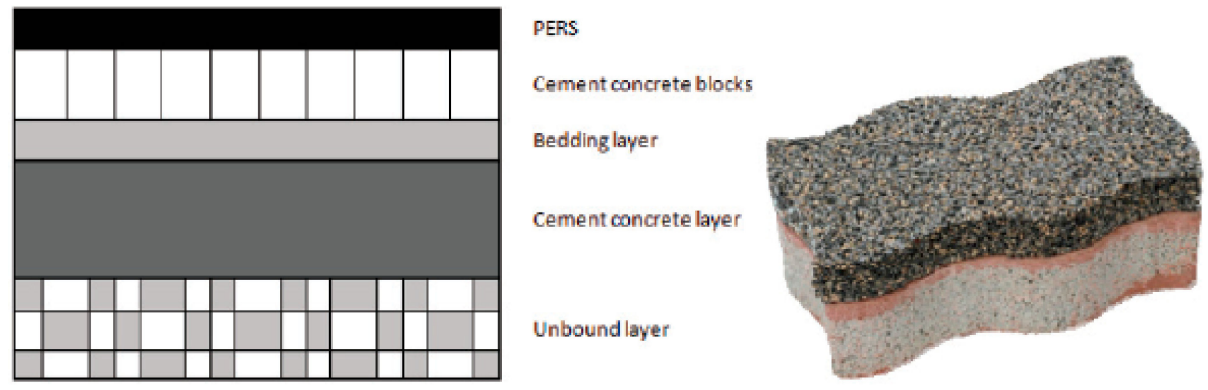

Figure 9. Porous elastic road surface samples [59].

\subsection{Twin Layer Courses}

Twin layers were first developed in the Netherlands in the 1990s and were originally called twinlay because of the two porous layers with different gradations (Figure 10). This solution has been proven to have good performance in mitigating noise at the source and has some of the porous asphalt course's similar pros and cons, like reducing splash and spray effects. Moreover, since it has two layers, the top one acts as a filter, hindering clogging and preventing that the bottom layer from eventual clogs [60-62]. Studies have shown that the twin layer's noise reduction capabilities can reach up to 6-7 $d B(A)$ in reference to a standard Hot Mix Asphalt (HMA) [63-65].

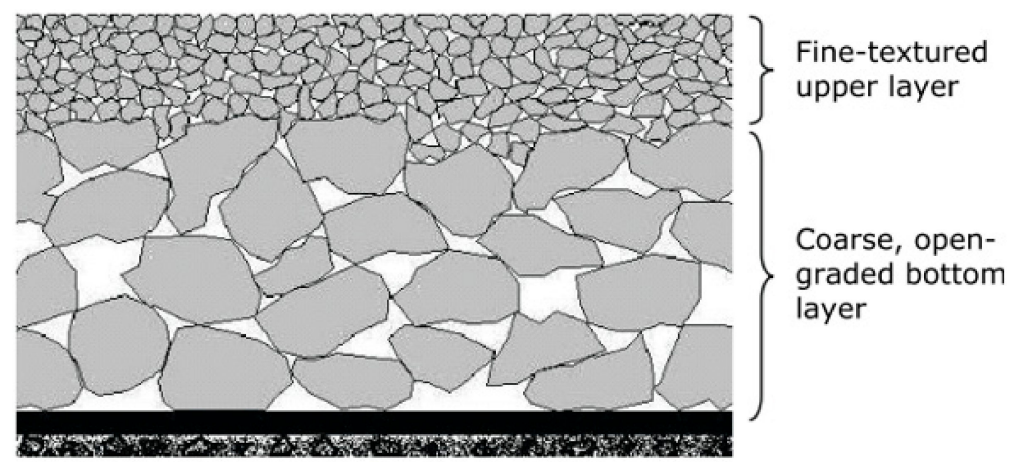

$15-30 \mathrm{~mm}$

Aggregate $2 / 5 \mathrm{~mm}$

$30-55 \mathrm{~mm}$

Aggregate $11 / 16 \mathrm{~mm}$

Figure 10. Twin layer scheme (adapted from [60]).

\subsection{High-Friction Surface Dressing (Nonbituminous)}

According to Woodward and Friel [66], a High Friction Surfaces is a special type of road coating with very high skid resistance, mainly used in locations with a high risk of accidents (including pedestrians), and it has been used in the UK since the 1960s. It is a cold applied mixture of selected aggregates (high resistance to abrasion and polishing) mixed with a bond coat resin (epoxy, polyurethane, resin, or acrylic) (Figure 11). These proprietary solutions are commercially available, and typically, they have a higher economic impact and do not aim to mitigate road noise. Nevertheless, in specific design scenarios, such as intersections, it has been shown that, in optimal conditions, they can abate up to $5 \mathrm{~dB}(\mathrm{~A})$ of noise [3]. 


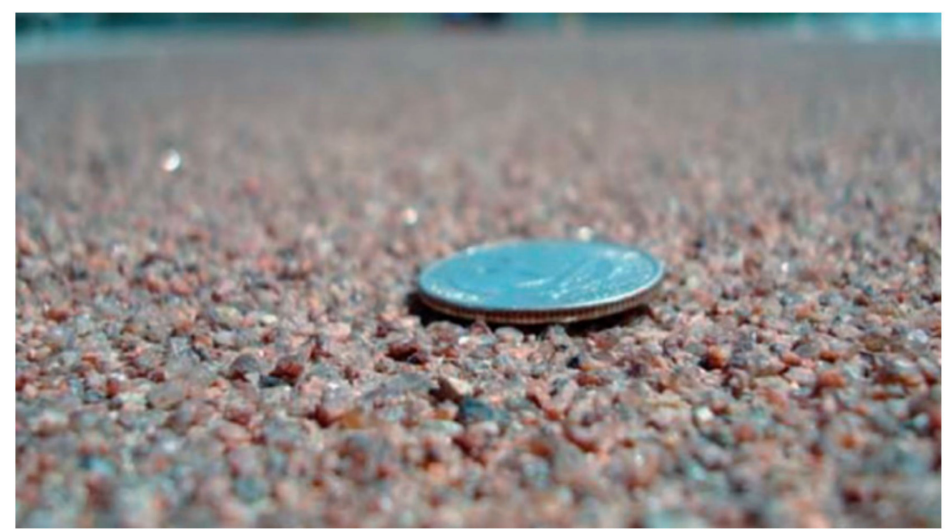

Figure 11. High-friction surface dressing.

\subsection{Microsurfacings}

Microsurfacings are polymer-modified, binder emulsion-based, dense-graded, coldmixed, and quick-setting asphalt surfacing materials. They are a widely used solution for pavement maintenance and increasing safety. They act as a protective wearing course that can be applied over the existing pavement, thus reducing some irregularities and filling cracks. They provide a surface with a regular and even texture, as shown in Figure 12. Microsurfacings are well known as a construction method with economic and environmental benefits $[26,67,68]$. Apart from the proven positive effects in terms of skid resistance, recent studies were conducted to assess their performance in terms of noise reduction when a specific mix gradation and powdered rubber were used in combination [68].

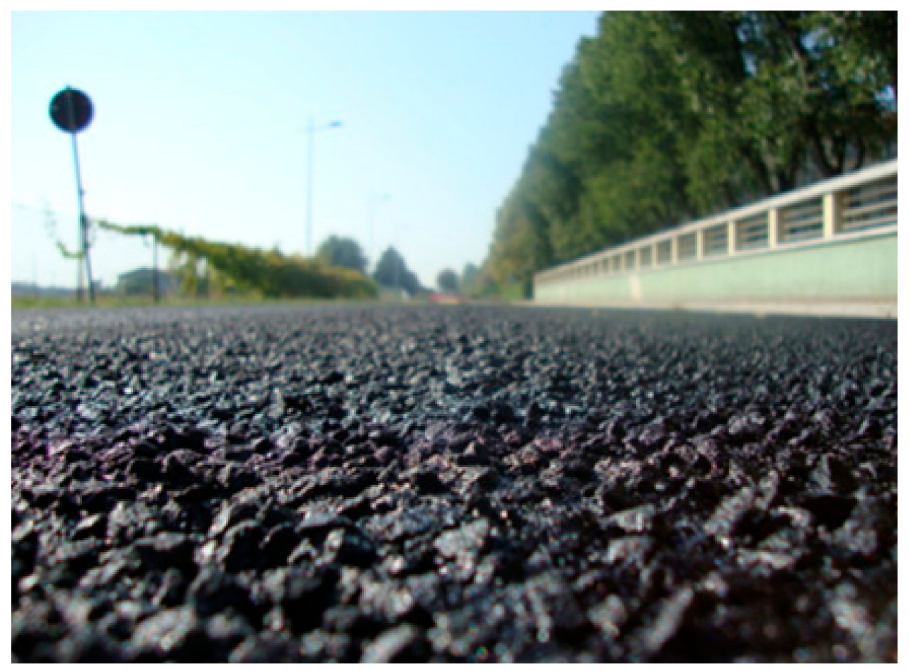

Figure 12. Cold laid acoustic microsurfacing at an Italian experimental site [69].

Table 1 provides the typical values of skid resistance, given in traditional BPN units, and noise levels in terms of the absolute sound pressure levels. It is important to recall that these values can be found in the literature. They are referred to as specific admixtures in terms of constituents, proportions, aggregate size, and physical characteristics. 
Table 1. Typical friction and noise characteristics of different paving solutions.

\begin{tabular}{cccc}
\hline Paving Solution & Friction (BPN) & Noise (dB(A)) & Reference \\
\hline Dense-Graded Hot Mix Asphalt & $60-65$ & $>84$ & {$[48,70]$} \\
Open-Graded Friction Courses & $50-80$ & $76-80$ & {$[50,51,71]$} \\
Stone Mastic Asphalt (SMA) & $50-65$ & $-10 \mathrm{~dB}(\mathrm{~A})$ reduction ${ }^{1}$ & {$[53-56]$} \\
Porous Elastic Road Surface (PERS) & 60 & $-6 \mathrm{~dB}(\mathrm{~A})$ reduction ${ }^{1}$ & {$[57,59,72-74]$} \\
Twin Layer Courses & Like open-graded courses & $-5 \mathrm{~dB}\left(\right.$ A) reduction ${ }^{1}$ & {$[62,63]$} \\
High-Friction Surface Dressing & Up to 90 & $69-75$ & {$[52,75,76]$} \\
Microsurfacings & $54-72$ & {$[68,77]$} \\
\hline
\end{tabular}

${ }^{1}$ The reduction is in reference to a standard hot mix asphalt called the ISO surface (ISO 10844:2011).

\section{High-Friction Acoustic Surface Pavements}

Surface treatments, especially those using cold binders, play a major role in the development of more sustainable and safer pavements. This paving solution (valid both for new constructions and maintenance interventions) shows promising results in terms of friction performance and can also be specifically designed to address noise. This is still under research and has been recently addressed as a high-friction acoustic surface for road pavements, in order to distinguish it from the high-friction surface dressing.

The most advanced high-friction acoustic surface pavement (HiFASP) makes use of engineered artificial aggregates partially made of waste materials, which are applied in slurry seals or microsurfacings on a new or existing road, as they are not designed to bring any structural benefit to the pavement.

The HiFASP-engineered artificial aggregates must be polish- and abrasion-resistant and be shaped in an Archimedean solid that enables space-filling as well as their handling, mixing, laying, and eventual repairing in a bound layer. They can be used along with other natural or recycled particles or fillers to form the so-called aggregate matrix. The engineered layer should provide a surface with designed homogeneous micro and macrotextures that can abate noise pollution and increase skid resistance if compared with a standard friction surfacing. Furthermore, as the HiFASP is an innovative solution that has the high-friction surface treatment basis in its conceptual background, it becomes mandatory to focus research on its durability and recyclability.

\subsection{HiFASP with Natural Aggregates}

Aggregates used in traditional high-friction surfaces are selected to have a concentrated distribution of high contact pressures in the tire-pavement interaction surface, thus eventually providing higher skid resistance. To achieve such a surface property, it is necessary to use specific aggregates to ensure the aimed skid resistance and guarantee a sufficient life span under the common traffic wearing actions.

According to Woodward et al. [66], the aggregate particles must be extremely hardwearing to maintain their sharp edges and must not become rounded or wear away under the stresses of turning or braking tires. The traffic, in fact, tends to polish the aggregate, thus reducing the friction, as is shown in the schematic graph of Figure 13.

Figure 13 shows that the friction changes over time. At first, traffic causes abrasion that removes the thin binder film on the aggregates, consequently exposing their microtexture and therefore usually developing additional skid resistance. This microtexture is usually worn off over time, mainly due to polishing, and reducing the overall friction. Therefore, the correct selection of aggregates is important to achieve the desirable wear resistance and thus the sought durable skid resistance. The aggregate can be natural, artificial or industrial, recycled, or even specifically engineered, as is described in the following section. Some research was conducted to evaluate the quality of the aggregates $[27,60,62]$, in which natural and artificial aggregates were compared through specific polishing tests (e.g., the well-known polished stone value [71]), as well as the surface texture and surface behavior. In the niche literature, authors classified the aggregates through their PSVs as shown in Table 2. For instance, it can be seen that the best PSV values were obtained for calcined 
bauxite [68] and sandstone. According to the author's laboratory work, the aggregates were crushed to obtain cube-shaped particles. Table 2 also presents the texture depth and pendulum test results for the tests performed on asphalt concrete specimens.

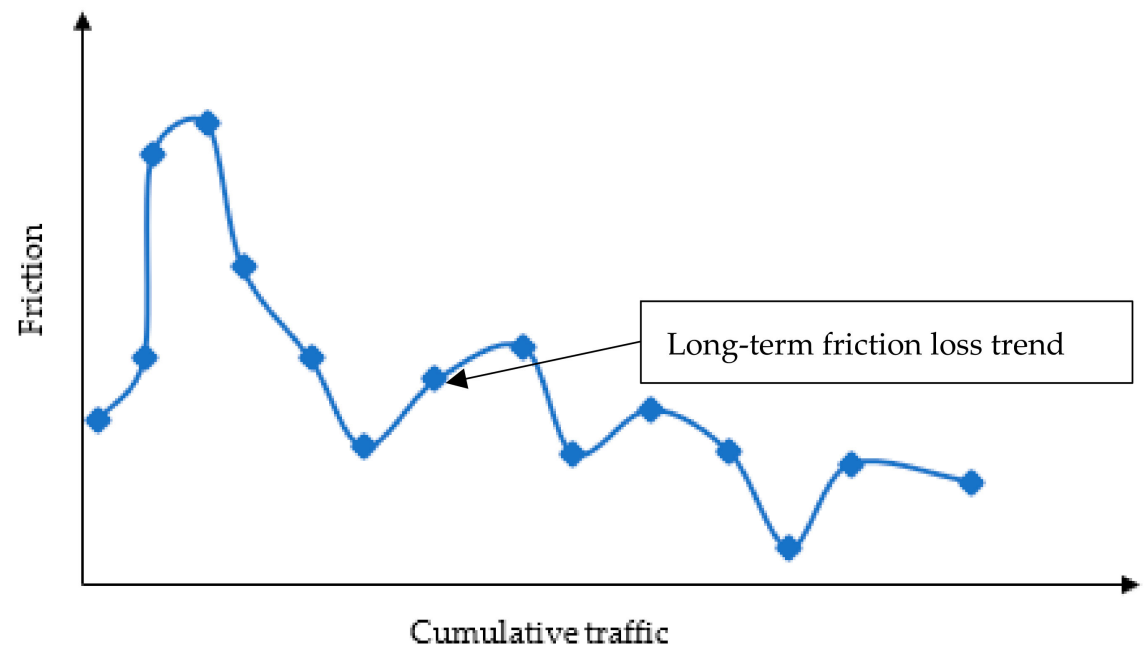

Figure 13. Possible development of friction over time for asphalt pavements (adapted from [76]).

Table 2. Different types of natural aggregates used in high-friction mixtures, showing polished stone values (PSVs) and asphalt surface characteristics.

\begin{tabular}{cccc}
\hline Rock Type & $\begin{array}{c}\text { PSV } \\
\text { (EN 1097-8:2009) }\end{array}$ & $\begin{array}{c}\text { Pendulum Test (PTN) } \\
\text { (ASTM E303:1991) }\end{array}$ & $\begin{array}{c}\text { Texture Depth (mm) (ISO } \\
\text { 13473-1:2019) }\end{array}$ \\
\hline Limestone A & 40 & 82 & 3.29 \\
Limestone B & 54 & 89 & 3.35 \\
Greywacke A & 65 & 81 & 3.32 \\
Greywacke B & 68 & 85 & 3.26 \\
Granite A & 55 & 87 & 3.47 \\
Granite B & 55 & 84 & 3.18 \\
Sandstone & 70 & 98 & 3.05 \\
Quartzite & 58 & 91 & 3.10 \\
Basalt & 53 & 95 & 3.74 \\
Calcined Bauxite & $70+$ & 89 & 3.10 \\
\hline
\end{tabular}

Table 2 shows that high pendulum tester numbers (PTNs) and a higher texture depth are not related. The difference in PTNs is highly dependent on the aggregate type, which also affects the PSV and the surface texture depth, denoting the importance of selecting specific aggregates to achieve high levels of friction.

Similarly, the selection of aggregates is very relevant to the pavement surface's actual noise emissions, as the origin, mineralogy, and production processes of natural aggregates, and especially their nominal size and gradation, strongly affect their contribution to the overall pavement acoustic performance. The literature states that to achieve a low road noise impact, it is crucial to create open- or gap-graded gradation curves with aggregate sizes no larger than $10 \mathrm{~mm}[3,19]$. As shown in the example graph of Figure 14, for the same type of pavement layer, only changing the aggregate size can induce a sound level difference of about $1 \mathrm{~dB}(\mathrm{~A})$, even after years of traffic. 


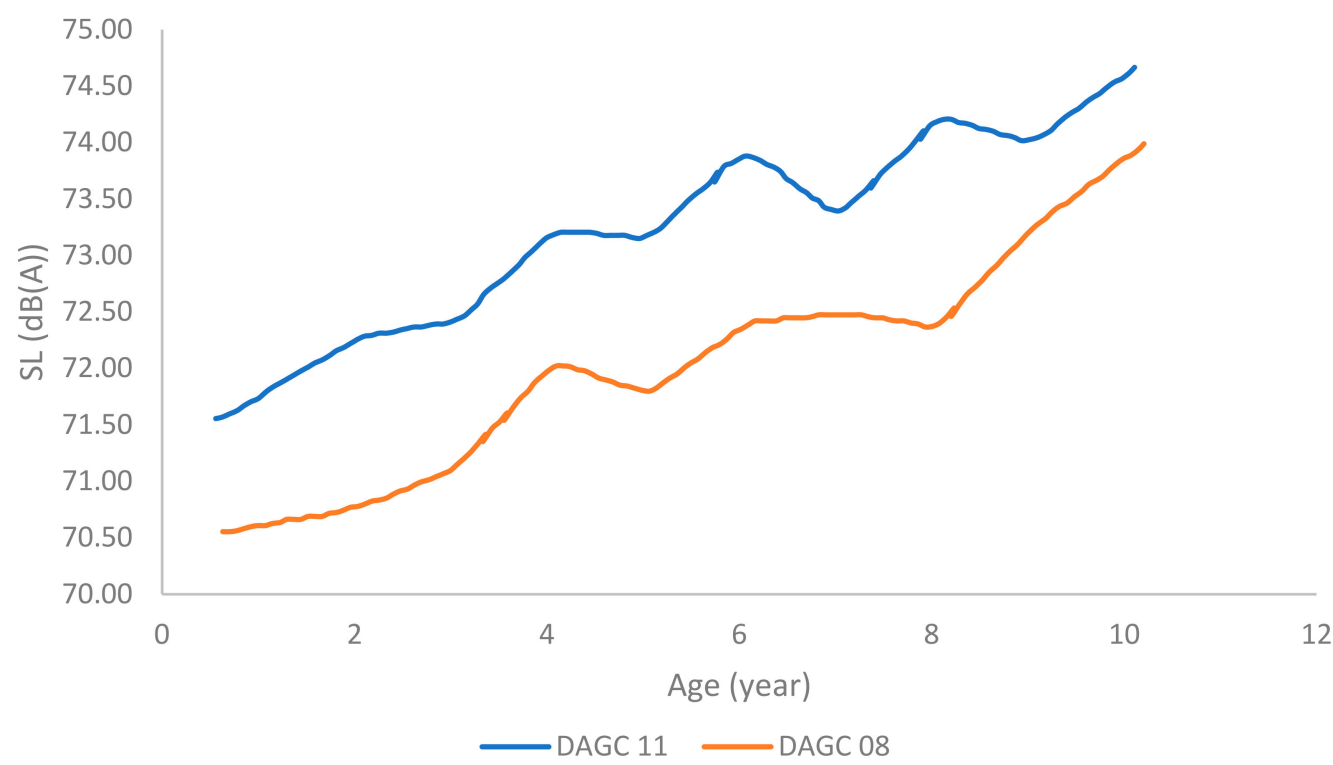

Figure 14. Noise evolution over time for a passenger car at $60 \mathrm{~km} / \mathrm{h}$ for dense-graded asphalt concrete with $11 \mathrm{~mm}$ and $8 \mathrm{~mm}$ maximum aggregate sizes (adapted from [78]).

Aggregates with a small maximum aggregate size tend to generate a texture with fewer peaks, therefore being smoother if compared to the average size of rubber tire treads. Their shape is also relevant, as cubic aggregates will allow the pavement to have a more negative texture [19,78]. However, to control noise, it is important not only to select the aggregates and their mixtures, but also the compaction method during construction or even consider the use of surface grooving techniques. Indeed, grooving or grinding techniques are more common for cement concrete pavements, with reported results ranging from $1.5 \mathrm{~dB}(\mathrm{~A})$ to $3.0 \mathrm{~dB}(\mathrm{~A})$ reductions relative to traditional asphalt concretes [78]. The grinding technique can also be applied to asphalt pavements, with results in terms of noise levels ranging from $3 \mathrm{~dB}(\mathrm{~A})$ to $5 \mathrm{~dB}(\mathrm{~A})$ when compared with the previous existing surface $[19,79]$. This reduction is mainly due to the effects of the grinding process, which eliminates the peaks, thus giving a final, more negative texture.

\subsection{HiFASP with Artificial Aggregates}

The use of artificial engineered aggregates for the construction of HiFASPs can appear to be a challenge. On one hand, they can be considered environmentally friendly, as they can reduce the need for virgin aggregates, while on the other hand, they might have higher costs associated with the achievement of specific physical and mechanical properties. Nevertheless, the latter aspect could be overcome with the use of waste constituents and low-energy production techniques, and their added value will reside in that they can be designed to a specific shape, size, and even microtexture to be used in HiFASPs.

The use of artificial engineered aggregates in pavements is still under research, but interest is growing around it. One of the first successful attempts was to create artificial lightweight aggregates (LWAs) made from clay waste minerals [80]. Recent studies have shown promising results, as surface layers containing LWAs could achieve friction levels above the requirements $(0.30-0.35 \mathrm{~F} 60$, the friction number at $60 \mathrm{~km} / \mathrm{h})$. As for the noise levels, according to the same specific literature, a reduction of $3 \mathrm{~dB}(\mathrm{~A})$ could be achieved even with traditional artificial LWAs [81].

The use of geopolymers or alkali-activated materials can have a predominant role in the development of artificial engineered aggregates for HiFASPs or other paving solutions. In fact, those materials can be produced with specific waste powders generated from different industrial processes (e.g., mining, milling, sawing, and washing) and transformed into castable construction elements, including engineered aggregates. Indeed, recent and ongoing studies on the use of geopolymers or Alkali-Activated Mixtures (AAM) for 
the production of aggregates and mixtures are promising [67,82-84]. Nonetheless, with respect to their use in HiFASPs and other severe wearing surface conditions, additional research must be conducted to guarantee their durability, recyclability, and avoid any potential environmental impact. Finally, it is straightforward that the use of artificial engineered aggregates can provide opportunities in the ways of smartening the pavements by embedding specific sensors and carrying different materials that can provide self-healing, self-sensing, and temperature-controlling features in the pavement layers $[85,86]$.

\section{Conclusions}

Safety and health are of paramount importance when designing pavements, especially in the context of growing traffic. These aspects must be considered in order to find appropriate paving solutions. In light of the proposed review, it is possible to infer the following final remarks:

- Solutions for improving skid resistance and noise exist and are currently used in many roads worldwide. They require a specific design of the pavement texture to address one or both aspects;

- Aggregates are commonly natural and virgin, and for this reason, a careful selection is needed for their use in pavements, providing specific skid resistance and acoustic characteristics;

- Artificial aggregates can be engineered to the desired shape, size, and microtexture so that specific characteristics can be implemented into the pavement layers. In particular, their design can guarantee enhanced skid resistance and acoustic performance;

- HiFASPs represent a new solution that can make use of artificial engineered aggregates, bringing road safety, human health, and environmental advantages. These can also be seen as highly reproducible, thus providing spatial and time homogeneity to the quality of road pavements worldwide;

- $\quad$ Engineered aggregates can become a tool for the implementation of different smart paving solutions. In these terms, future pavements are very likely to be a pattern of engineered surfaces having different functions and characteristics for different locations and uses.

Author Contributions: Conceptualization, S.C.C. and C.S.; methodology, S.C.C.; writing-original draft preparation, S.C.C.; writing-review and editing, C.S.; supervision, C.S. All authors have read and agreed to the published version of the manuscript.

Funding: This research was funded by the European Union's Horizon 2020 research and innovation program under the Marie Sklodowska-Curie grant agreement $\mathrm{N}^{\circ} 765057$.

Conflicts of Interest: The authors declare no conflict of interest.

\section{References}

1. Plati, C.; Pomoni, M.; Georgouli, K. Quantification of skid resistance seasonal variation in asphalt pavements. J. Traffic Transp. Eng. 2019, 7, 237-248. [CrossRef]

2. Afonso, M.L.; Dinis-Almeida, M.; Fael, C.S. Characterization of the Skid Resistance and Mean Texture Depth in a Permeable Asphalt Pavement. IOP Conf. Ser. Mater. Sci. Eng. 2019, 471, 22029. [CrossRef]

3. Sandberg, U.; Ejsmont, J.A. Tyre/Road Noise Reference Book, 1st ed.; INFORMEX Ejsmont and Sandberg Handelsbolag: Kisa, Sweden, 2002; ISBN 91-613-2610-9.

4. Rado, Z.; Kane, M. An initial attempt to develop an empirical relation between texture and pavement friction using the HHT approach. Wear 2014, 309, 233-246. [CrossRef]

5. Kogbara, R.B.; Masad, E.A.; Kassem, E.; Scarpas, A.; Anupam, K. A state-of-the-art review of parameters influencing measurement and modeling of skid resistance of asphalt pavements. Constr. Build. Mater. 2016, 114, 602-617. [CrossRef]

6. Tsubota, T.; Fernando, C.; Yoshii, T.; Shirayanagi, H. Effect of Road Pavement Types and Ages on Traffic Accident Risks. Transp. Res. Procedia 2018, 34, 211-218. [CrossRef]

7. Puzzo, L.; Loprencipe, G.; Tozzo, C.; D'Andrea, A. Three-dimensional survey method of pavement texture using photographic equipment. Measurement 2017, 111, 146-157. [CrossRef]

8. Klüppel, M.; Heinrich, G. Rubber Friction on Self-Affine Road Tracks. Rubber Chem. Technol. 2000, 73, 578-606. [CrossRef] 
9. Edmondson, V.; Woodward, J.; Lim, M.; Kane, M.; Martin, J.; Shyha, I. Improved non-contact 3D field and processing techniques to achieve macrotexture characterisation of pavements. Constr. Build. Mater. 2019, 227, 116693. [CrossRef]

10. Frei, P.; Mohler, E.; Röösli, M. Effect of nocturnal road traffic noise exposure and annoyance on objective and subjective sleep quality. Int. J. Hyg. Environ. Health 2014, 217, 188-195. [CrossRef] [PubMed]

11. Swinburn, T.K.; Hammer, M.S.; Neitzel, R.L. Valuing Quiet: An Economic Assessment of U.S. Environmental Noise as a Cardiovascular Health Hazard. Am. J. Prev. Med. 2015, 49, 345-353. [CrossRef] [PubMed]

12. Pardillo Mayora, J.M.; Jurado Piña, R. An assessment of the skid resistance effect on traffic safety under wet-pavement conditions. Accid. Anal. Prev. 2009, 41, 881-886. [CrossRef]

13. Woodward, W.D.; Woodside, A. Early and mid life SMA skid resistance. In Proceedings of the Safer Road Conference, Auckland, New Zealand, 2-4 May 2014; pp. 1-10.

14. Haider, M.; Descornet, G.; Sandberg, U.; Pratico, F.G. Road Traffic Noise Emission: Recent Develpments and Future. In Proceedings of the 4th International SIIV Congress, Palermo, Italy, 12-14 September 2007.

15. International Organization for Standardization. ISO Characterization of Pavement Texture by Use of Surface Profiles-Part. 3: Specification and Classification of Profilometers; ISO 13473-3; ISO: Vernier, Switzerland, 2002; p. 3.

16. Praticò, F.; Vaiana, R. A study on the relationship between mean texture depth and mean profile depth of asphalt pavements. Constr. Build. Mater. 2015, 101, 72-79. [CrossRef]

17. Rezaei, A.; Masad, E.; Chowdhury, A. Development of a Model for Asphalt Pavement Skid Resistance Based on Aggregate Characteristics and Gradation. J. Transp. Eng. 2012, 137, 863-873. [CrossRef]

18. Roger, N.; Abbott, P.; Andersen, B.; Anfosso-Ledee, F.W.; Bendtsen, B.H.; van Blokland, G.D. Silvia-Sustainable Road Surface for Traffic Noise Control; Technical Report; Guy Descornet: Brussel, Belgium, 2006; ISBN 9789090204048.

19. Vieira, T.; Sandberg, U.; Erlingsson, S. Negative texture, positive for the environment: Effects of horizontal grinding of asphalt pavements. Road Mater. Pavement Des. 2019, 22, 1-22. [CrossRef]

20. Knabben, R.M.; Trichês, G.; Gerges, S.N.; Vergara, E.F. Evaluation of sound absorption capacity of asphalt mixtures. Appl. Acoust. 2016, 114, 266-274. [CrossRef]

21. Del Pizzo, A.; Teti, L.; Moro, A.; Bianco, F.; Fredianelli, L.; Licitra, G. Influence of texture on tyre road noise spectra in rubberized pavements. Appl. Acoust. 2020, 159, 107080. [CrossRef]

22. Davies, B.R.; Cenek, D.P.; Henderson, J.R. The effect of skid resistance and texture on crash risk. In Proceedings of the International Surface Friction Conference, Christchurch, New Zealand, 1-4 May 2005; p. 17.

23. Andriejauskas, T.; Vorobjovas, V.; Mielonas, V. Evaluation of skid resistance characteristics and measurement methods. In Proceedings of the 9th International Conference Environmental Engineering, Vilnius, Lithuania, 22-24 May 2014. [CrossRef]

24. Wambold, J.C.; Henry, J.J. International PIARC experiment to compare and harmonize texture and skid resistance measurements. In Nordic Road and Transport Research; Swedish National Road and Transport Research Institute (VTI): Linköping, Sweden, 1994.

25. World Health Organization. A Road Safety Technical Package; WHO: Geneva, Switzerland, 2017; ISBN 9789241511704.

26. Ivan, J.N.; Ravishanker, N.; Jackson, E.; Aronov, B.; Guo, S. A Statistical Analysis of the Effect of Wet-Pavement Friction on Highway Traffic Safety. J. Transp. Saf. Secur. 2012, 4, 116-136. [CrossRef]

27. Fwa, T. Skid resistance determination for pavement management and wet-weather road safety. Int. J. Transp. Sci. Technol. 2017, 6, 217-227. [CrossRef]

28. Singh, D.; Patel, H.; Habal, A.; Das, A.K.; Kapgate, B.P.; Rajkumar, K. Evolution of coefficient of friction between tire and pavement under wet conditions using surface free energy technique. Constr. Build. Mater. 2019, 204, 105-112. [CrossRef]

29. Ueckermann, A.; Wang, D.; Oeser, M.; Steinauer, B. Calculation of skid resistance from texture measurements. J. Traffic Transp. Eng. 2015, 2, 3-16. [CrossRef]

30. Hall, J.W.; Smith, K.L.; Titus-Glover, L.; Wambold, J.C.; Yager, T.J.; Rado, Z. Guide for Pavement Friction; Transportation Research Board: Washington, DC, USA, 2009.

31. Kane, M.; Rado, Z.; Timmons, A. Exploring the texture-friction relationship: From texture empirical decomposition to pavement friction. Int. J. Pavement Eng. 2015, 16, 919-928. [CrossRef]

32. Gabriel, P.; Thomas, A.; Busfield, J. Influence of interface geometry on rubber friction. Wear 2010, 268, 747-750. [CrossRef]

33. European Comission. Report from the Commission to the European Parliament and the Council on the Implementation of the Environmental Noise Directive in Accordance with Article 11 of Directive 2002/49/EC; European Comission: Brussels, Belgium, 2017 ; Volume 151.

34. Dzhambov, A.M.; Lercher, P. Road Traffic Noise Exposure and Birth Outcomes: An Updated Systematic Review and Meta-Analysis. Int. J. Environ. Res. Public Health 2019, 16, 2522. [CrossRef] [PubMed]

35. Dzhambov, A.M.; Lercher, P. Road Traffic Noise Exposure and Depression/Anxiety: An Updated Systematic Review and Meta-Analysis. Int. J. Environ. Res. Public Health 2019, 16, 4134. [CrossRef] [PubMed]

36. Simões, M.R.L.; Souza, C.; De Alcantara, M.A.; Assunção, A. Ávila Precarious working conditions and health of metropolitan bus drivers and conductors in Minas Gerais, Brazil. Am. J. Ind. Med. 2019, 62, 996-1006. [CrossRef] [PubMed]

37. World Health Organization. Burden of Disease from Burden of Disease; WHO: Geneva, Switzerland, $2011 ;$ p. 126.

38. Imagine Project. Available online: http://www.imagine-project.org/ (accessed on 20 December 2020).

39. Ramussen, R.O.; Bernhard, R.J.; Sandberg, U.; Mun, E.P. The Little Book of Quieter Pavements; Federal Highway Administration and the Transtec Group: Washington, DC, USA, 2007; pp. 1-33. 
40. Paje, S.E.; Vazquez, V.F.; Teran, F.; Vinuela, U. Study of a road test track with and without crumb rubber: Solutions for noise pollution. Environ. Eng. Manag. J. 2014, 13, 2487-2495. [CrossRef]

41. Vázquez, V.F.; Luong, J.; Bueno, M.; Terán, F.; Paje, S.E. Assessment of an action against environmental noise: Acoustic durability of a pavement surface with crumb rubber. Sci. Total. Environ. 2016, 542, 223-230. [CrossRef]

42. Praticò, F.G. On the dependence of acoustic performance on pavement characteristics. Transp. Res. Part. D Transp. Environ. 2014, 29, 79-87. [CrossRef]

43. Umnova, O.; Attenborough, K.; Shin, H.-C.; Cummings, A. Deduction of tortuosity and porosity from acoustic reflection and transmission measurements on thick samples of rigid-porous materials. Appl. Acoust. 2005, 66, 607-624. [CrossRef]

44. Kim, H.; Lee, H. Acoustic absorption modeling of porous concrete considering the gradation and shape of aggregates and void ratio. J. Sound Vib. 2010, 329, 866-879. [CrossRef]

45. Siebert, D. How Wear Affects Road Surface Texture and Its Impact on Tire/Road Noise Texture; NTNU Norwegian University of Science and Technology: Trondheim, Norway, 2017.

46. International Organization for Standardization. Acoustics-Measurement of the Influence of Road Surfaces on Traffic Noise-Part. 2: The Close-Proximity Method; ISO/DIS 11819-2; ISO: Vernier, Switzerland, 2014.

47. American Society for Testing and Materials. Standard Practice for Calculating International Friction Index of a Pavement Surface; ASTM E1960-07; ASTM: West Conshohocken, PA, USA, 2015.

48. Li, W.; Han, S.; Huang, Q. Performance of Noise Reduction and Skid Resistance of Durable Granular Ultra-Thin Layer Asphalt Pavement. Materials 2020, 13, 4260. [CrossRef] [PubMed]

49. Alvarez, A.E.; Martin, A.E.; Estakhri, C.K.; Button, J.W.; Glover, C.J.; Jung, S.H. Synthesis of Current Practice on the Design, Construction, and Maintenance of Porous Friction Courses; Report No. FHWA/TxDOT 0-5262-1; Texas Transportation Institute: Bryan, TX, USA, 2006; Volume 7.

50. Wu, H.; Yu, J.; Song, W.; Zou, J.; Song, Q.; Zhou, L. A critical state-of-the-art review of durability and functionality of open-graded friction course mixtures. Constr. Build. Mater. 2020, 237, 117759. [CrossRef]

51. Aybike Ongel, J.; Harvey, T.; Kohler, E.; Lu, Q.; Steven, B.D. Investigation of Noise, Durability, Permeability, and Friction Performance Trends for Asphalt Pavement Surface Types: First-and Second-Year Results; University of California: Sacramento, CA, USA, 2008.

52. Woodward, D.; Millar, P.; Lantieri, C.; Sangiorgi, C.; Vignali, V. The wear of Stone Mastic Asphalt due to slow speed high stress simulated laboratory trafficking. Constr. Build. Mater. 2016, 110, 270-277. [CrossRef]

53. Tonin, R. Quiet Road Pavements: Design and Measurement-State of the Art. Acoust. Aust. 2016, 44, 235-247. [CrossRef]

54. Praticò, F.; Mark, S. Quiet Pavement Technologies; PIARC-2013R10EN; PIARC: Paris, France, 2013.

55. Wu, Y.; Parker, F.; Kandhal, P.S. Aggregate Toughness/Abrasion Resistance and Durability/Soundness Tests Related to Asphalt Concrete Performance in Pavements. Transp. Res. Rec. J. Transp. Res. Board 1998, 1638, 85-93. [CrossRef]

56. Wasilewska, M.; Gardziejczyk, W.; Gierasimiuk, P. Evaluation of Skid Resistance Using CTM, DFT and SRT-3 Devices. Transp. Res. Procedia 2016, 14, 3050-3059. [CrossRef]

57. Ejsmont, J.; Świeczko-Żurek, B.; Owczarzak, W.; Sommer, S.; Ronowski, G. Tire/Road Noise on Poroelastic Road Surfaces. EuroNoise 2018, 2018, 2719-2724.

58. Meiarashi, S. Porous Elastic Road Surface as Urban Highway Noise Measure. Transp. Res. Rec. J. Transp. Res. Board 2004, 1880, 151-157. [CrossRef]

59. Goubert, L.; Bendtsen, H.; Bergiers, A.; Kalman, B.; Kokot, D. The Poroelastic Road Surface (PERS): Is the 10 dB Reducing Pavement within Reach? Mater. Infrastruct. 2016, 1, 253-268. [CrossRef]

60. Persuade. Available online: http:/ / persuade.fehrl.org (accessed on 22 January 2021).

61. Morgan, P.A.; Stait, R.E.; Reeves, S.; Clifton, M. The Feasibility of Using Twin-Layer Porous Asphalt Surfaces on England's Strategic Road Network; PPR433; Transport Research Laboratory: Berkshire, UK, 2007; p. 106.

62. Bernhard, R.; Wayson, R.A. An Introduction to Tire/Pavement Noise of Asphalt pavement; Institute of Safe, Quiet and Durable Highways: West Lafayette, IN, USA, 2005; p. 26.

63. Tang, G.Q.; Li, M.L.; Ji, T.J.; Liu, Z. Current Status of Research on Two-Layer Porous Asphalt. Appl. Mech. Mater. 2014, 716-717, 443-447. [CrossRef]

64. Kragh, J.; Bendtsen, H. Performance of New Twin-Lay Drainage Asphalt Laid in Denmark. In Proceedings of the 29th International Congress and Exhibition on Noise Control Engineering, Nice, France, 27-30 August 2000; pp. 2-7.

65. Liu, M.; Huang, X.; Xue, G. Effects of double layer porous asphalt pavement of urban streets on noise reduction. Int. J. Sustain. Built Environ. 2016, 5, 183-196. [CrossRef]

66. Woodward, D.; Friel, S. Predicting the Wear of High Friction Surfacing Aggregate. Coatings 2017, 7, 71. [CrossRef]

67. Robati, M.; Carter, A.; Perraton, D. Evaluation of test methods and selection of aggregate grading for type III application of micro-surfacing. Int. J. Pavement Eng. Asph. Technol. 2013, 14, 11-35. [CrossRef]

68. Karyawan, I.D.A.; Ahyudanari, E.; Ekaputri, J.J. Potential Use of Fly Ash Base-Geopolymeras Aggregate Substitution in Asphalt Concrete Mixtures. Int. J. Eng. Technol. 2017, 9, 3744-3752. [CrossRef]

69. Sangiorgi, C.; Bitelli, G.; Lantieri, C.; Irali, F.; Girardi, F. A Study on Texture and Acoustic Properties of Cold Laid Microsurfacings. Procedia Soc. Behav. Sci. 2012, 53, 223-234. [CrossRef]

70. Grilli, A.; Graziani, A.; Carter, A.; Sangiorgi, C.; Specht, L.P.; Callai, S.C. Slurry surfacing: A review of definitions, descriptions and current practices. RILEM Tech. Lett. 2019, 4, 103-109. [CrossRef] 
71. Freitas, E.; Pereira, P.A.A.; Santos, L.P.; Santos, A.P.S. A Influência da Água no Ruído Produzido pelo Tráfego Rodoviário. Eng. Civ. 2006, 26, 5-15.

72. Goubert, L. A new test track with the ultra noise reducing Poro-elastic Road Surface (PERS) in Gent, Belgium. In Proceedings of the INTER-NOISE-48th International Congress Exhibition on Noise Control Engeering, Madrid, Spain, 16-19 June 2019.

73. Fujiwara, T.; Meiarashi, S.; Namikawa, Y.; Hasebe, M. Reduction of equivalent continuous A-weighted sound pressure levels by porous elastic road surfaces. Appl. Acoust. 2005, 66, 766-778. [CrossRef]

74. Meiarashi, S.; Ishida, M.; Fujiwara, T.; Hasebe, M.; Nakatsuji, T. Noise reduction characteristics of porous elastic road surfaces. Appl. Acoust. 1996, 47, 239-250. [CrossRef]

75. Friel, S. High Friction Surface Coating and Method of Making Thereof. U.S. Patent 9,739,017, 22 August 2017.

76. Heitzman, M.; Turner, P.; Greer, M. High Friction Surface Treatment Alternative Aggregates Study; National Center for Asphalt Technology: Auburn, AL, USA, 2015.

77. Nowoświat, A.; Sorociak, W.; Żuchowski, R. The impact of the application of thin emulsion mat microsurfacing on the level of noise in the environment. Constr. Build. Mater. 2020, 263, 120626. [CrossRef]

78. Conférence Européenne des Directeurs des Routes. State of the Art in Managing Road Traffic Noise: Noise-Reducing Pavements Noise-Reducing; CEDR: Tucson, AZ, USA, 2017; ISBN 9791093321271.

79. McIntosh, J.; Wong, F.; Macha, P.; Buret, M. Long term acoustic performance of different asphalt configurations. In Proceedings of the Acoustics 2019, Sound Decisions: Moving forward with Acoustics Annual Conference of the Australian Acoustical Society, Cape Schanck, Australia, 10-13 November 2019; pp. 1-10.

80. Losa, M.; Leandri, P.; Bacci, R.; Information, R. Mechanical and Performance-Related Properties of Asphalt Mixes Containing Expanded Clay Aggregate. Transp. Res. Rec. J. Transp. Res. Board 2008, 2051, 23-30. [CrossRef]

81. Tataranni, P.; Sangiorgi, C. Synthetic Aggregates for the Production of Innovative Low Impact Porous Layers for Urban Pavements. Infrastructures 2019, 4, 48. [CrossRef]

82. Solouki, A.; Viscomi, G.; Tataranni, P.; Sangiorgi, C. Preliminary Evaluation of Cement Mortars Containing Waste Silt Optimized with the Design of Experiments Method. Materials 2021, 14, 528. [CrossRef] [PubMed]

83. Gunasekara, C.; Setunge, S.; Law, D.W.; Willis, N.; Burt, T. Engineering Properties of Geopolymer Aggregate Concrete. J. Mater. Civ. Eng. 2018, 30, 1-11. [CrossRef]

84. Solouki, A.; Viscomi, G.; Lamperti, R.; Tataranni, P. Quarry Waste as Precursors in Geopolymers for Civil Engineering Applications: A Decade in Review. Materials 2020, 13, 3146. [CrossRef] [PubMed]

85. Birgin, H.B.; D'Alessandro, A.; Laflamme, S.; Ubertini, F. Hybrid Carbon Microfibers-Graphite Fillers for Piezoresistive Cementitious Composites. Sensors 2021, 21, 518. [CrossRef] [PubMed]

86. Birgin, H.B.; D’Alessandro, A.; Laflamme, S.; Ubertini, F. Smart Graphite-Cement Composite for Roadway-Integrated Weigh-InMotion Sensing. Sensors 2020, 20, 4518. [CrossRef] 